\title{
Towards Provenance Capturing of Quantified Self Data
}

Andreas Schreiber, Doreen Seider

German Aerospace Center (DLR), Cologne, Germany

Medando UG, Cologne, Germany

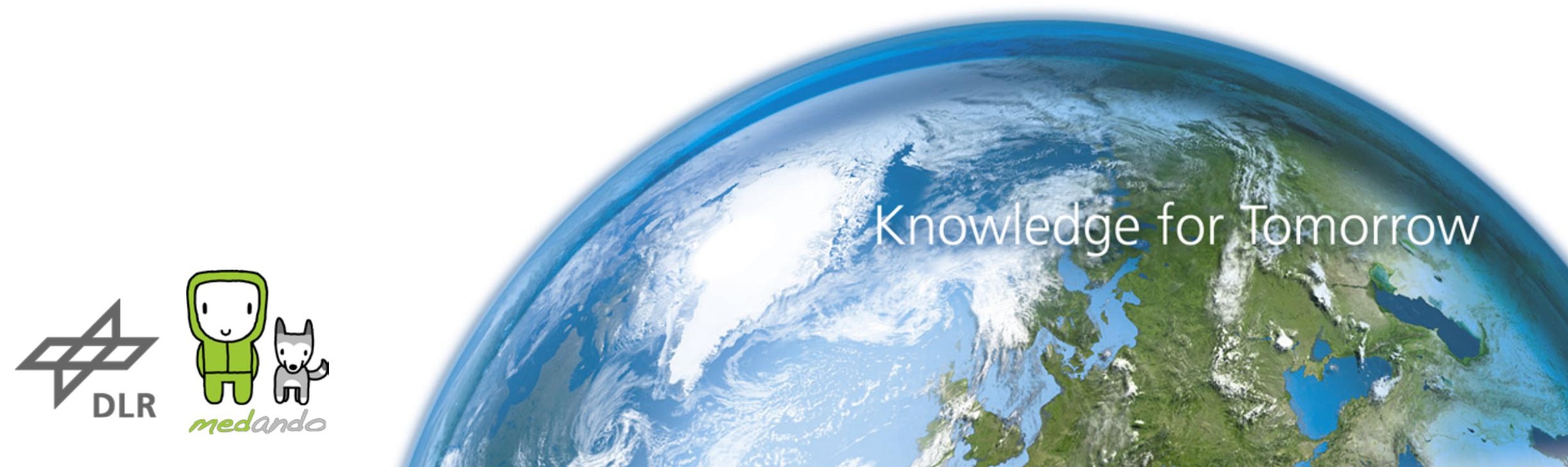




\section{Quantified Self - Self Tracking}

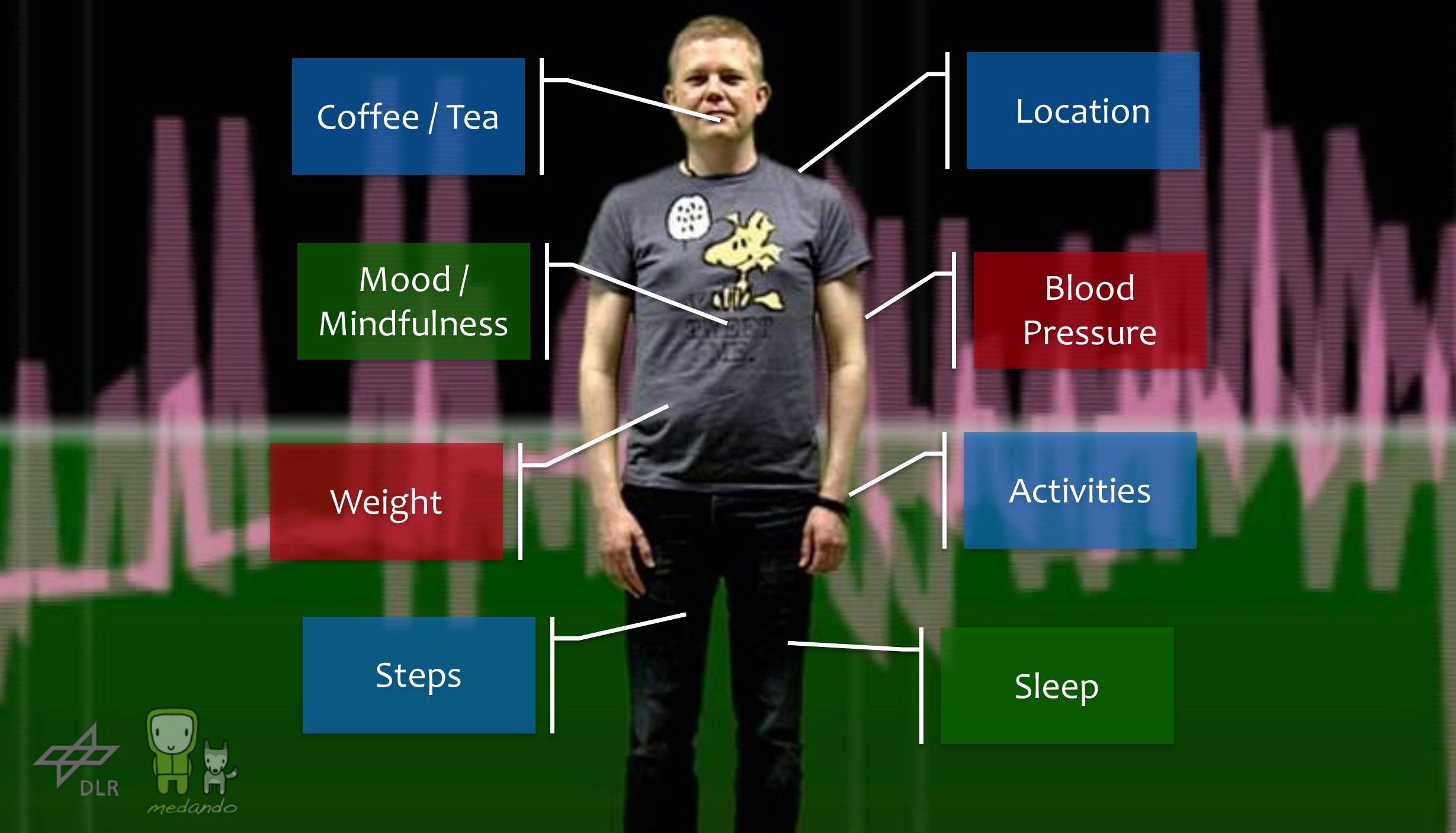




\section{Technology: Wearables - Apps - Services}

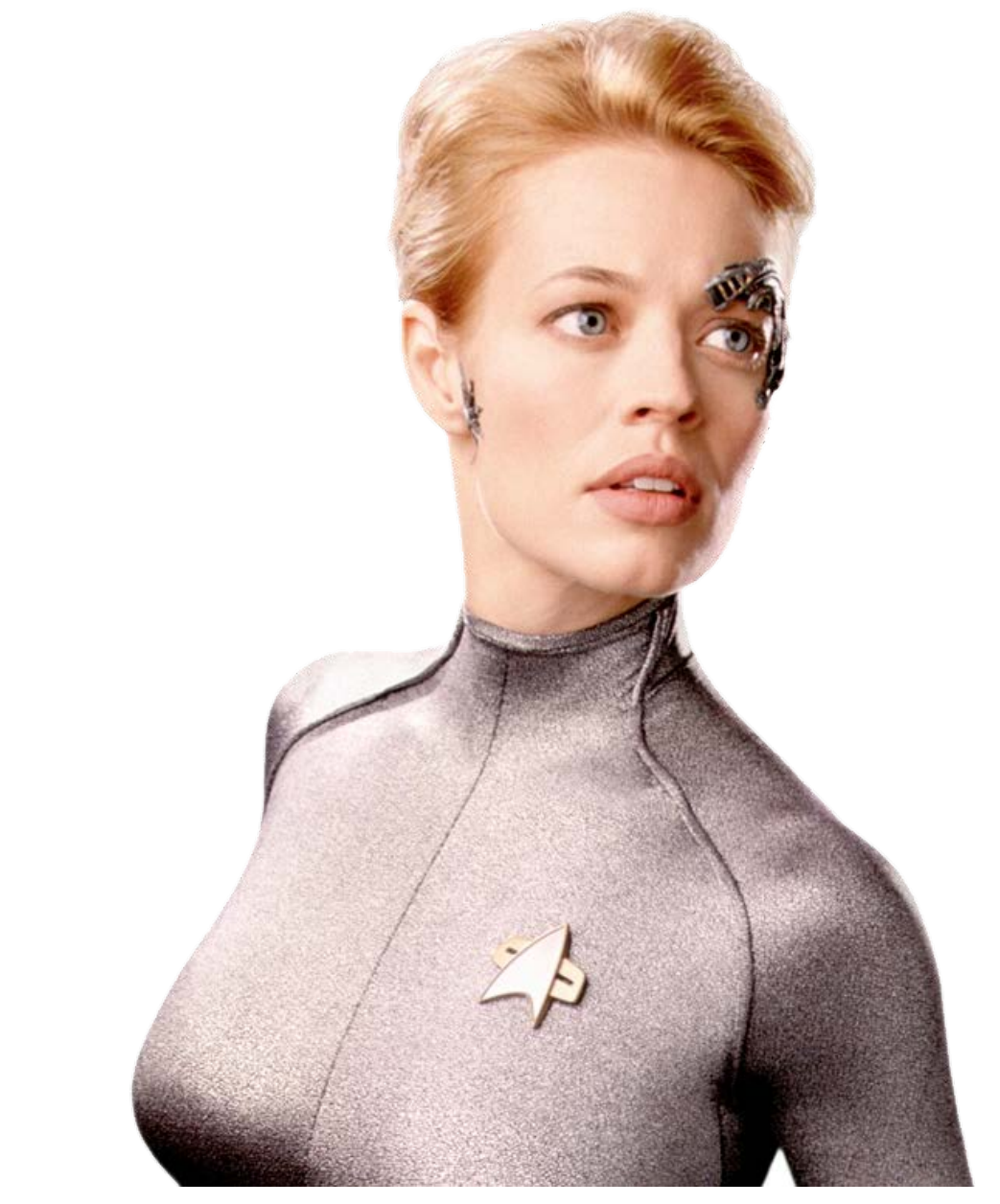

\section{Wearable Devices}

- Wearable, implantable, attachable, ingestible

- Embedded systems with sensors, Internet-of-things

\section{Apps}

- Smarthphone, desktop, webbased apps

- Aggregation portals

\section{Services}

-Web-services, cloud-services

- Provided by hardware vendors

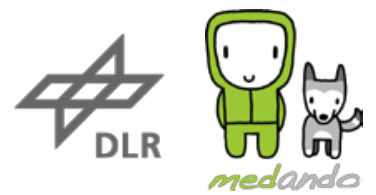




\section{Example: Weight Tracking}
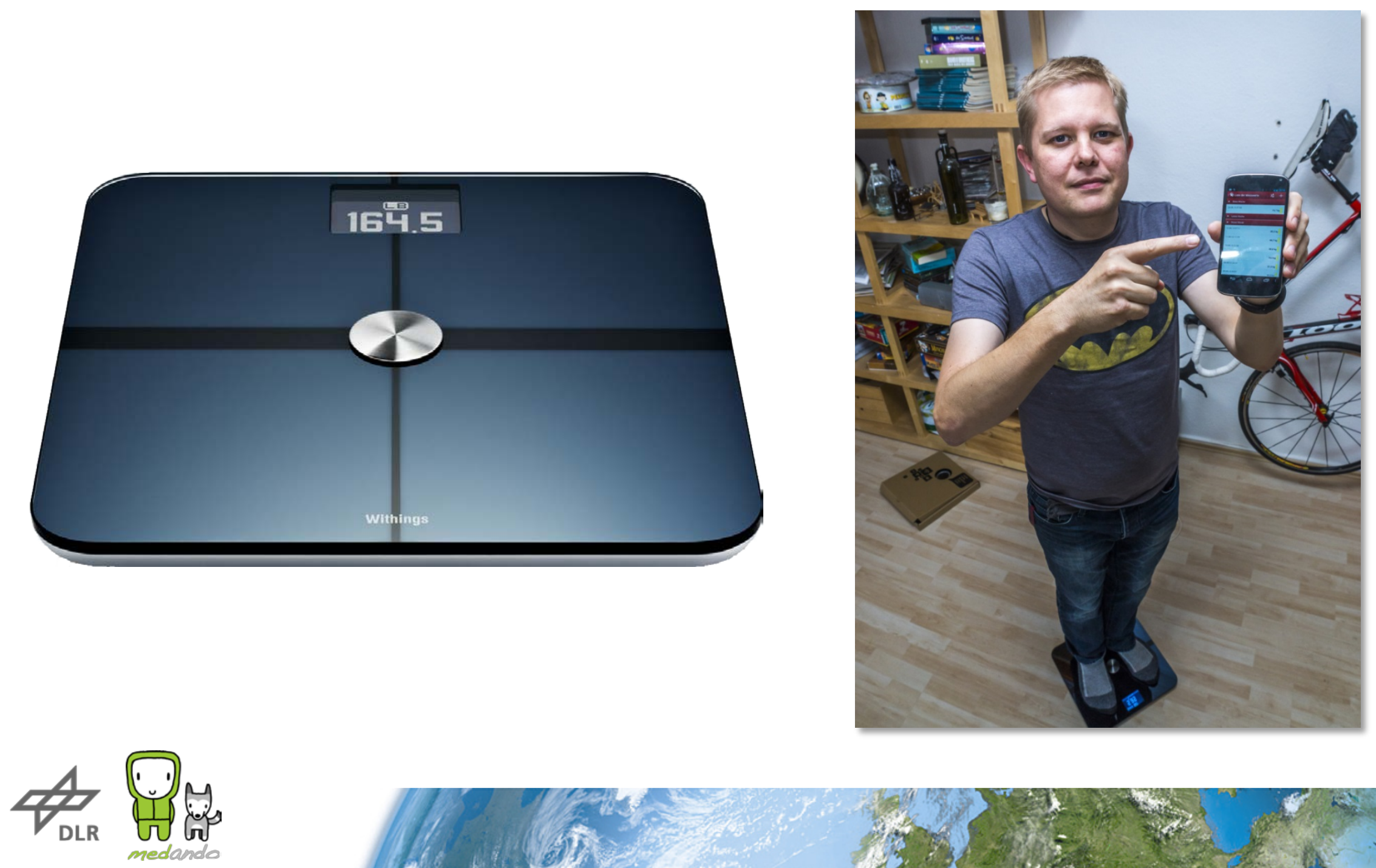


\section{Weight Tracking}
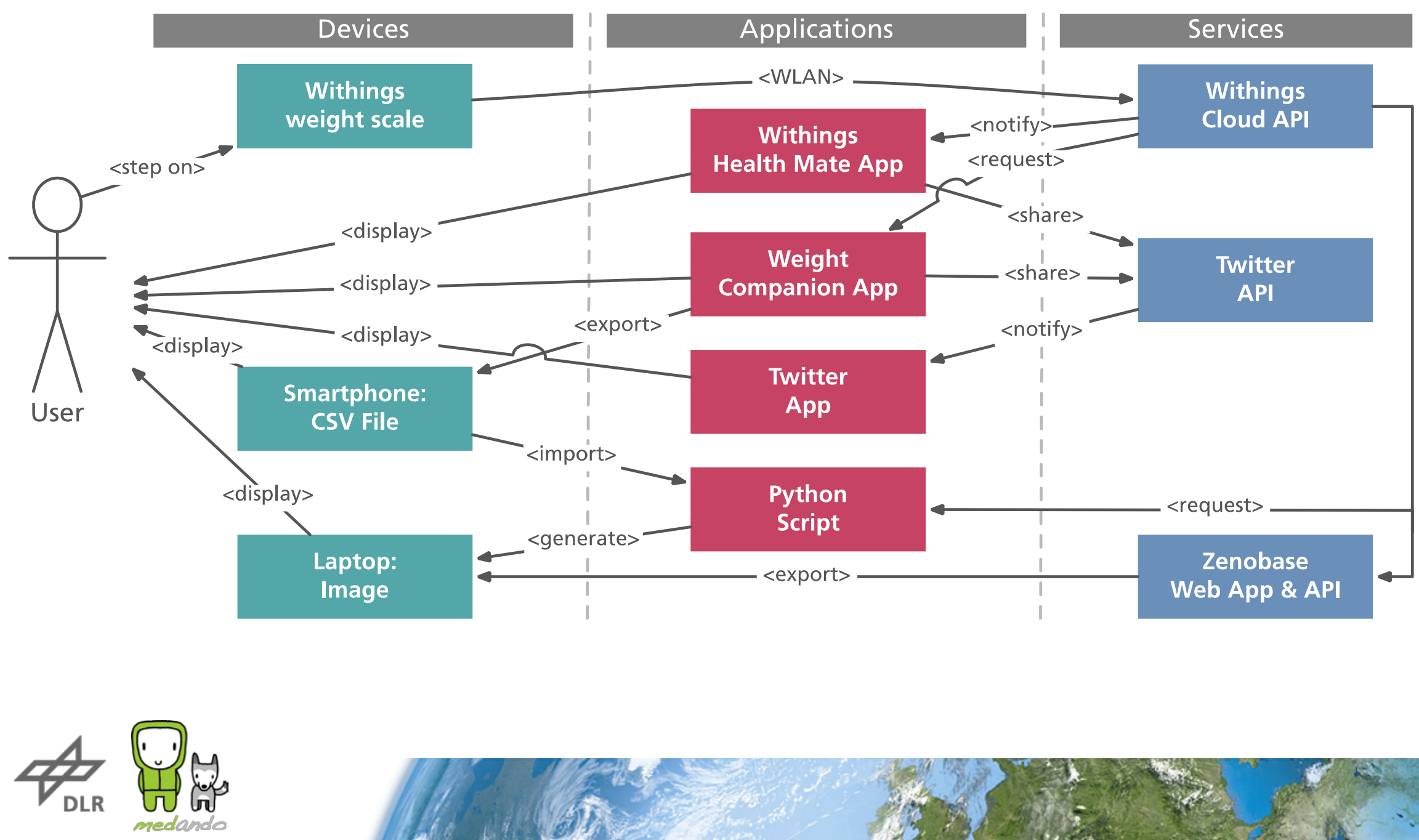


\section{Questions}

\begin{tabular}{|c|c|}
\hline $\begin{array}{l}\text { Entity- } \\
\text { focused }\end{array}$ & $\begin{array}{l}\text { - What data about the user were created during the } \\
\text { - What data about the user were automatically generated? } \\
\text { - What data about the user were derived from manual } \\
\text { input? }\end{array}$ \\
\hline $\begin{array}{l}\text { Activity- } \\
\text { focused }\end{array}$ & $\begin{array}{l}\text { - Which activities support visualization of the users data? } \\
\text { - In which activities can the user input data? } \\
\text { - What processes are communicating data? }\end{array}$ \\
\hline $\begin{array}{l}\text { Agent- } \\
\text { focused }\end{array}$ & $\begin{array}{l}\text { - What parties were involved in generating data } X \text { ? } \\
\text { - What parties got access on data } X \text { ? } \\
\text { - Can other parties see user's data } X \text { ? }\end{array}$ \\
\hline
\end{tabular}




\section{PROV Model for the Quantified Self („Templates")}
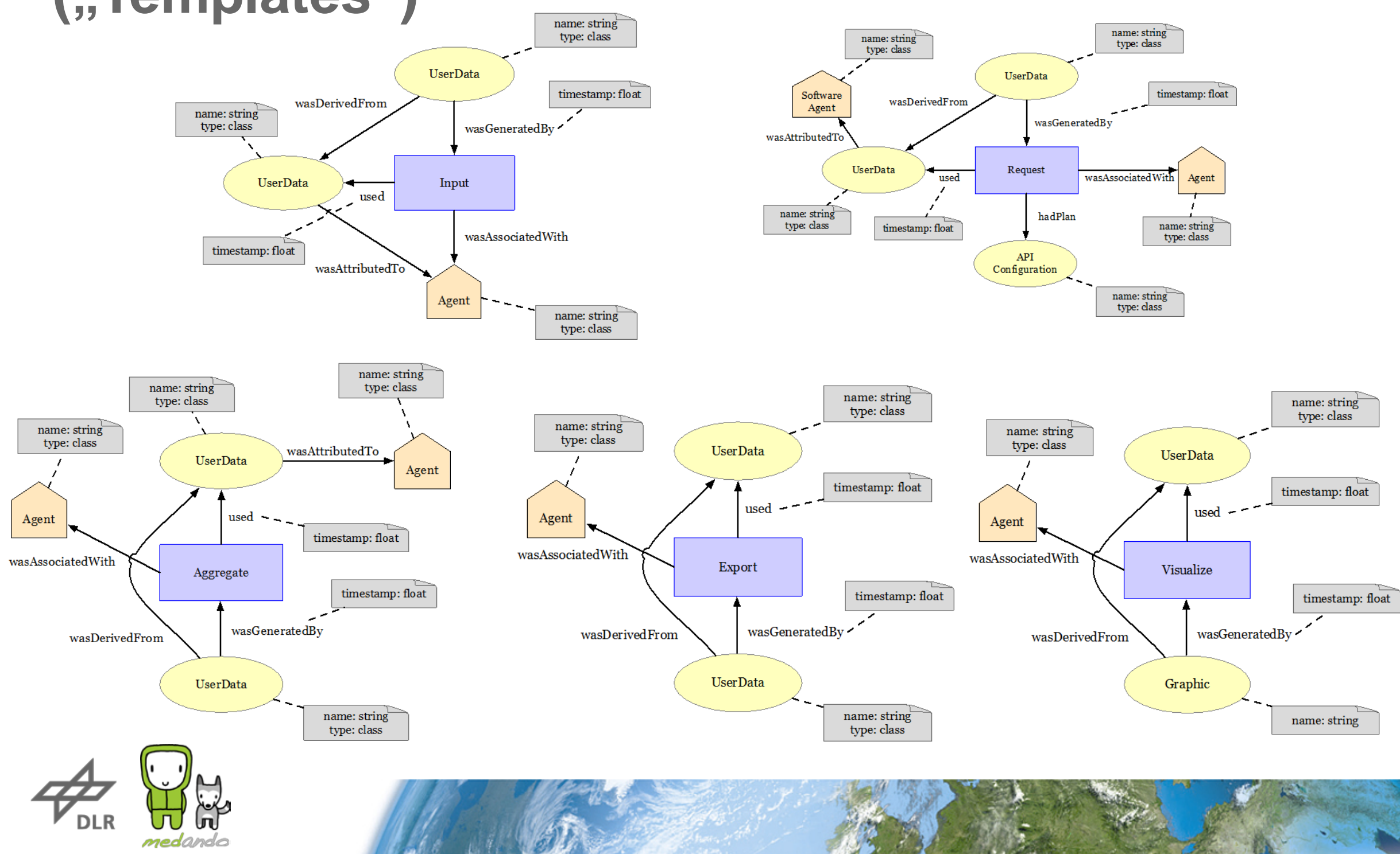


\section{Android App WeightCompanion}

GET IT ON Google Play

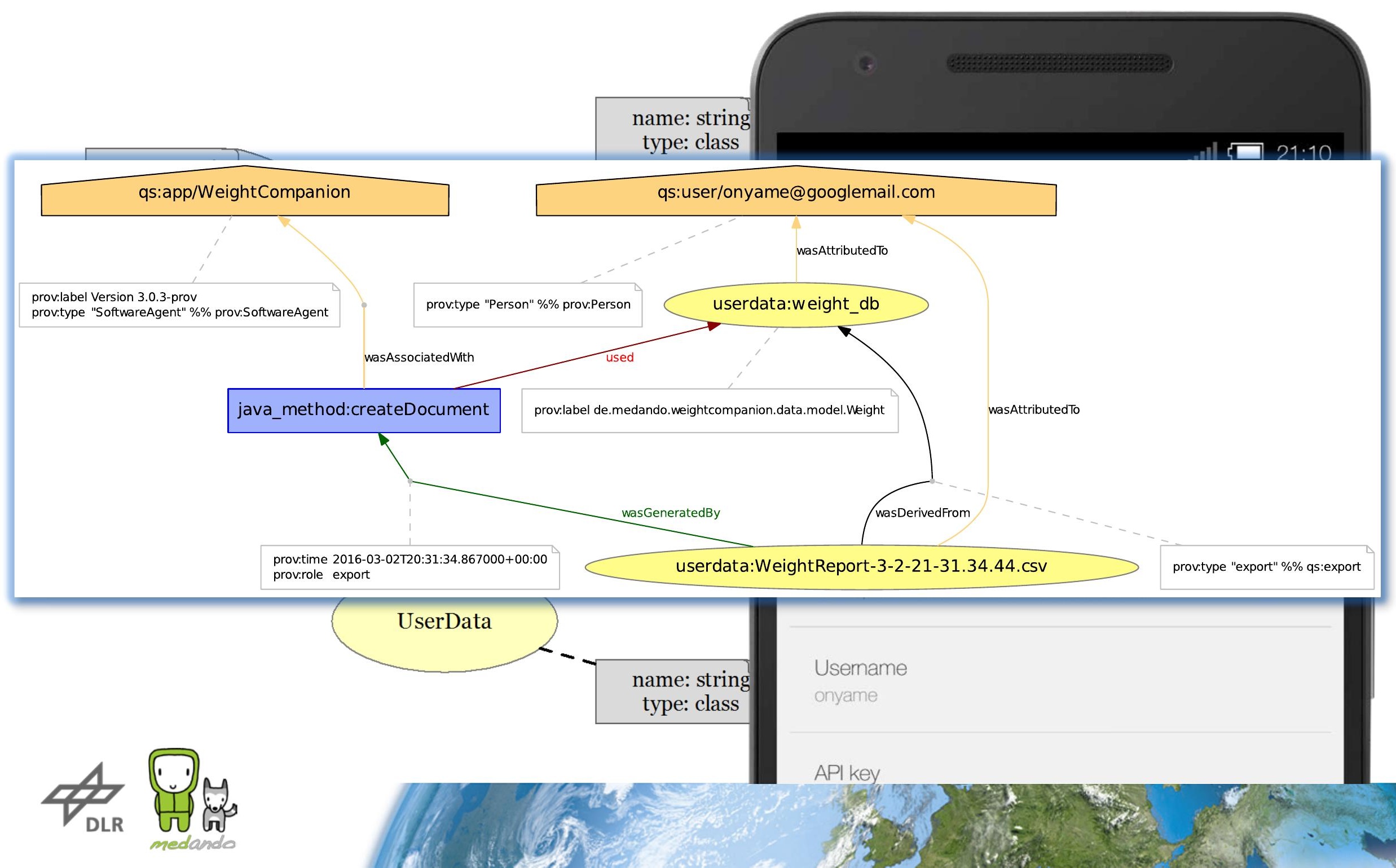




\section{Python Script}

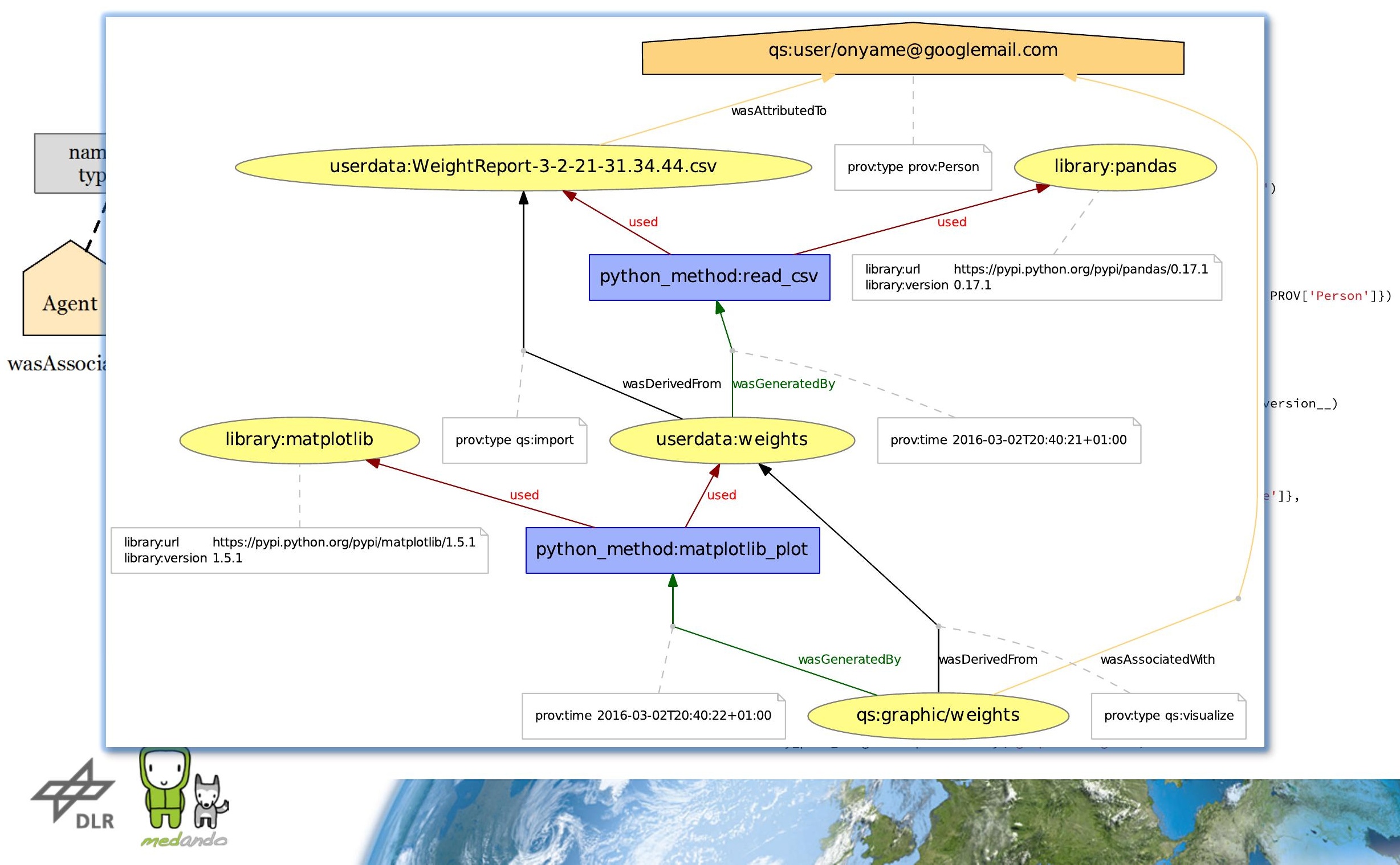




\section{Merging \& Storing: ProvToolbox \& ProvStore}
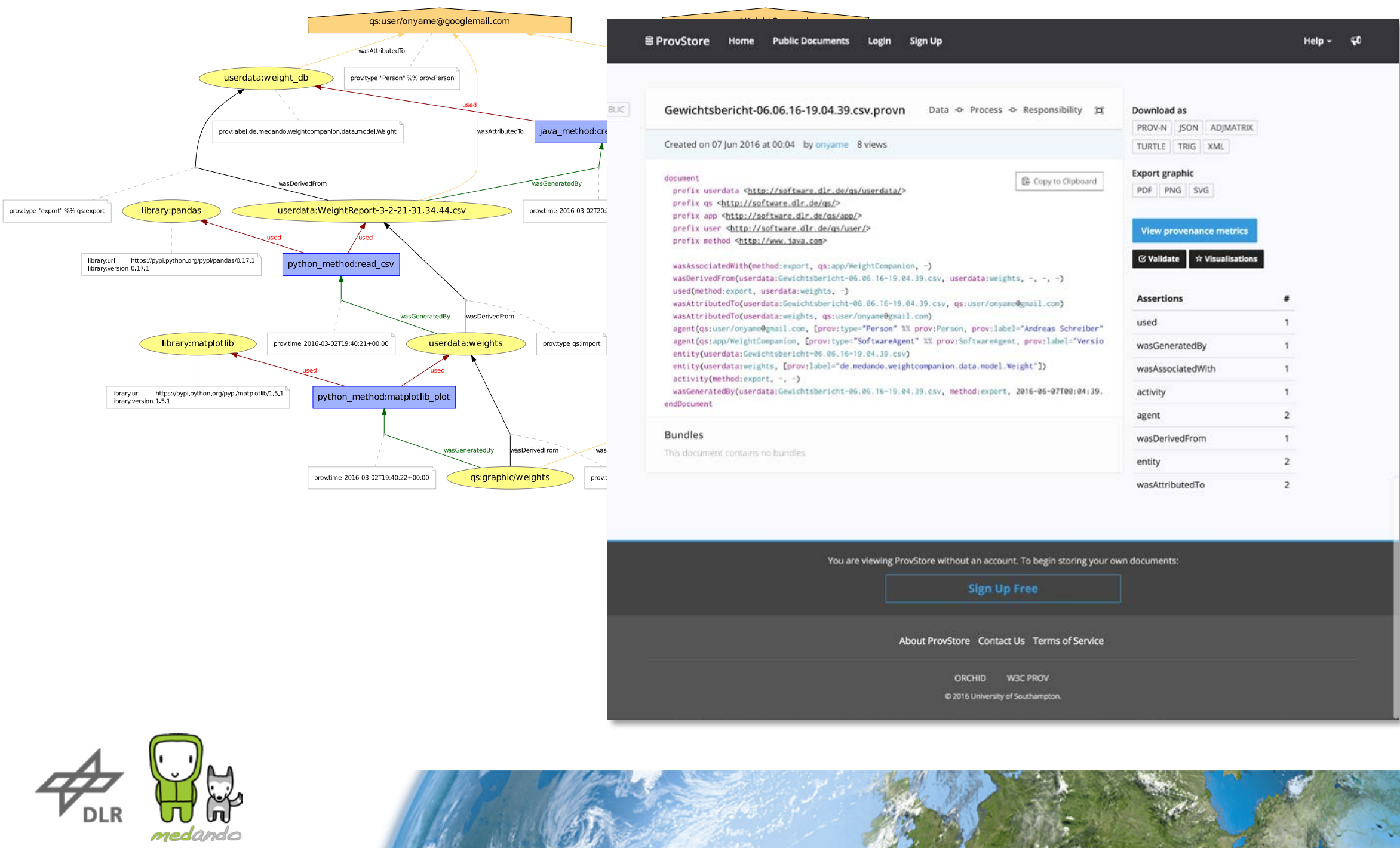


\section{Thank You!}

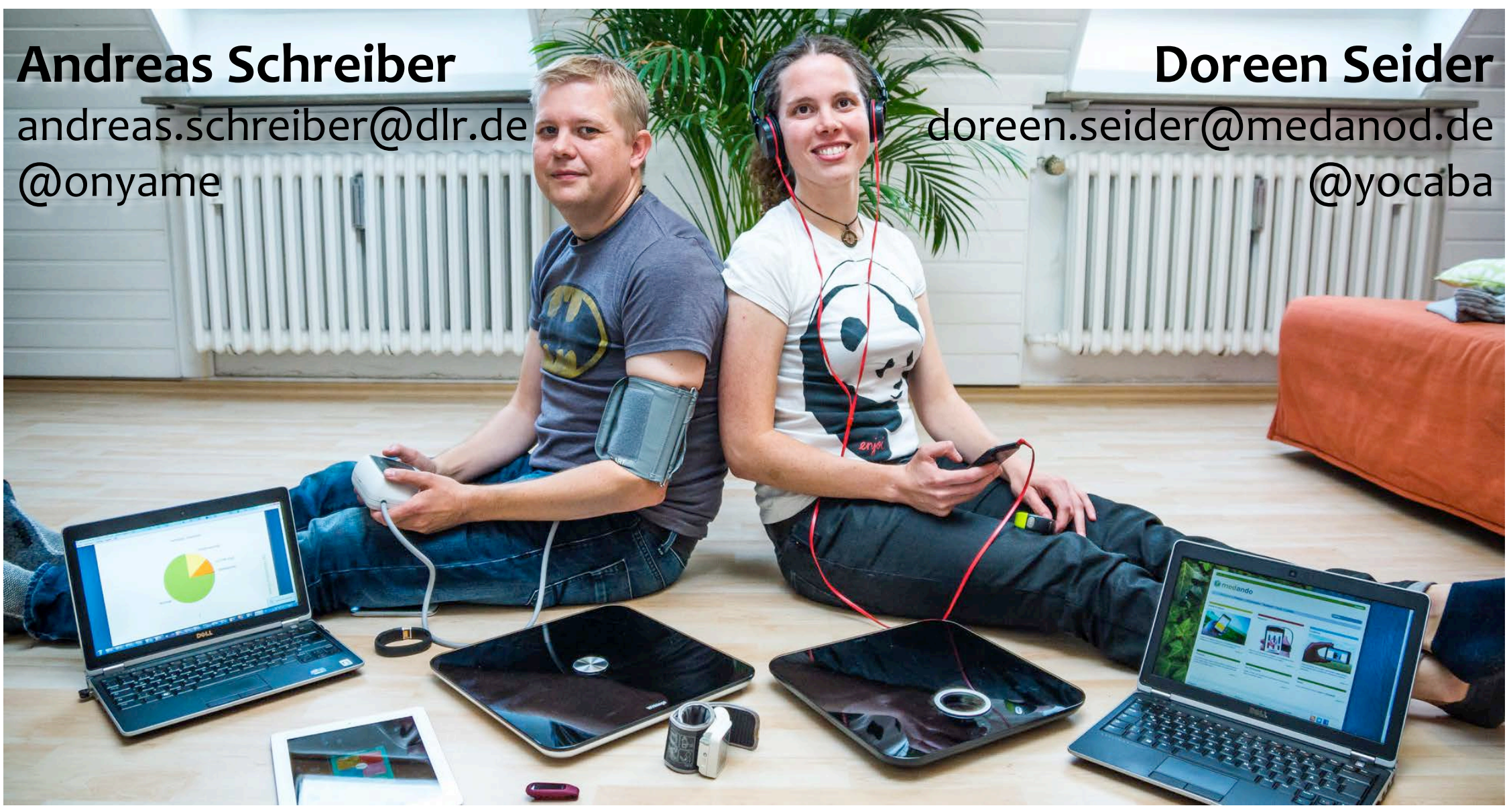

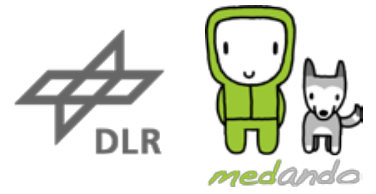

